\title{
Rat bite fever on Vancouver Island: 2010-2016
}

\author{
BN Hryciw ${ }^{1}$, CP Wright ${ }^{1}$, K Tan ${ }^{1,2 \star}$
}

\section{Abstract}

Background: Rat bite fever (RBF) is a rare bacterial zoonotic infection caused by Streptobacillus moniliformis and Spirillum minus, which are found naturally in rodent respiratory tracts. Recently, multiple cases of RBF were observed on Vancouver Island, British Columbia.

Objective: To conduct a case series analysis of cases of RBF on Vancouver Island between 2010 and 2016 to characterize the epidemiology, presentation, microbiology and treatment of RBF.

Methods: Cases were identified through queries of discharge diagnosis and microbiology laboratory information. Clinical details were collected through review of electronic and paper chart reviews of hospital documentation from Island Health.

Results: Eleven cases of RBF on Vancouver Island were identified between 2010 and 2016. Most cases of RBF were confirmed with identification of $S$. moniliformis by culture or molecular techniques. All cases presented with fever, and a subset had one or more of the following: myalgia, rash, polyarthralgia, joint effusions, and emesis. All cases were successfully treated with penicillin, ceftriaxone or doxycycline. Seven cases required hospitalization, but there were no deaths or significant morbidity.

Conclusion: This is the largest single case series of RBF in Canada. Diagnosis requires a high index of suspicion by clinicians and early intervention is necessary to prevent morbidity and mortality.

Suggested citation: Hryciw BN, Wright CP, Tan K. Rat bite fever on Vancouver Island: 2010-2016. Can Commun Dis Rep 2018;44(9):215-9. https://doi.org/10.14745/ccdr.v44i09a05

Keywords: Rat bite fever, zoonotic infection, Streptobacillus moniliformis, Spirillium minus

\author{
Affiliations \\ ${ }^{1}$ University of British Columbia, \\ Vancouver, BC \\ 2 BC's Agency for Pathology and \\ Laboratory Medicine, Vancouver, \\ $\mathrm{BC}$
}

*Correspondence: kennard.tan@ bccss.org

\section{Introduction}

Rat bite fever (RBF) is a rare zoonotic infection caused by gram-negative Streptobacillus moniliformis and Spirillium minus $(1,2)$. These bacteria are part of the commensal flora (i.e., the normal flora of the mouth) of healthy domesticated or laboratory rats (3). S. moniliformis is the predominant pathogen throughout North America, whereas $S$. minus is more prevalent in Asia where RBF is also known as "sodoku" $(4,5)$. RBF is aptly named as the classical cause of infection occurs through rodent bites; however, it can also occur through scratches or mucocutaneous contact with rodent saliva, urine or feces (4). Historically, the populations at risk for developing RBF were limited to laboratory personnel and those of low socioeconomic status (6). The domestication of rodents has led to a broadening of the epidemiology of $\mathrm{RBF}$ to include pet rodent owners and pet store employees $(6,7)$ and, with an increase in rodent handling, there has been a concomitant increase in rat bites. One report estimated 40,000 rat bites per year in the United States, of which, 2\% caused infection (8). Previous studies have noted that RBF represents a significant and potentially growing public health concern and consequently, there exists a need to better understand RBF clinically $(5,9)$.

\section{Clinical presentation, diagnosis and treatment}

Following inoculation of the pathogen, the incubation period for S. moniliformis is typically fewer than seven days but ranges from three days to three weeks (4). RBF is classically characterized by overt symptoms of fever, rigors, rash and polyarthralgia. Additional symptoms may include fatigue, emesis, myalgia, headache and pharyngitis (10). As symptoms are non-specific and variable, the clinical diagnosis of RBF is often missed if the history of rodent exposure is not identified. Infections by S. minus have a slightly different clinical presentation, with induration and possible ulceration of the bite site and associated adenopathy after a 14- to 18-day incubation (4). Complications of untreated RBF include the development of myocarditis, pericarditis, meningitis, amnionitis and abscesses in a variety of organs, as well as mortality in up to $13 \%$ of cases (11-14).

Recognition of RBF within the microbiology laboratory is often difficult and delayed given the fastidious nature of both S. moniliformis and $S$. minus $(1,4)$. The organisms are slow to cultivate and growth may be inhibited by substances within the culture media. Fortunately, the organisms are typically susceptible to a variety of antibiotics including beta-lactam antibiotics, clindamycin, erythromycin and tetracycline $(3,4)$. Among these, the recommended treatment is penicillin (15). 


\section{Canadian context}

Case reports of RBF in Canada were rarely documented until 2002 (16), although cases have been described in Canada since the early half of the $20^{\text {th }}$ century $(17,18)$. Subsequently, a total of seven cases of $S$. moniliformis infections were reported across Canada, predominantly in Ontario and Quebec (16,19-21). Most recently in 2013, a single case report from Vancouver Island was reported (22). Including that recent case, we have observed several confirmed cases of RBF on Vancouver Island since 2010.

The objective of this case series is to describe the etiology, epidemiology and clinical features of RBF amongst the population on Vancouver Island between 2010 and 2016. Secondary objectives are to examine patient outcomes, including the length of hospital stay, treatment and consequent sequelae.

\section{Methods}

\section{Setting and population}

Island Health is a regional health authority that provides inpatient and emergency patient care to all 765,000 residents of Vancouver Island. RBF cases were identified through queries of the Island Health's Enterprise Data Warehouse. Specifically, the queries were placed against the Discharge Abstract Database for admitted patients using ICD-10-CA (International Statistical Classification of Diseases and Related Health Problems, Tenth Revision, Canada) diagnosis codes for "Streptobacillosis" (A25.1) or "Rat-bite fever, unspecified" (A25.9), and against the microbiology laboratory information system for $S$. moniliformis or S. minus between January 2010 and December 2016. Patients with microbiological confirmation of either S. moniliformis or S. minus, or those with a history of rodent exposure and a compatible clinical syndrome, were included in this case series. Data was collected through retrospective chart reviews of identified cases regarding the clinical features upon presentation, treatment course provided and health outcomes. Institutional research ethics approval was sought and received for this study.

\section{Data collection and analysis}

Epidemiological and clinical details from identified cases were collected from hospital electronic medical records and paper charts. In particular, an attempt was made to record, where documented, any information regarding exposure source, including the context of interaction, such as bites, scratches or contact with either domestic, laboratory or wild rodents. The population data was analyzed using descriptive statistics to estimate the epidemiology, clinical features and outcomes between patients.

\section{Results}

Eleven cases of RBF were identified from Vancouver Island between 2010 and 2016 (Table 1). The median age of patients at diagnosis was 20 years old and ranged from five to 57 years of age. The cases were divided without significant gender bias, withfive male patients and six female patients. Nine patients reported a history of rodent exposure (82\%), all of which were
Table 1: Reported cases of rat bite fever on Vancouver Island from 2010 to 2016

\begin{tabular}{|c|c|c|c|c|c|c|}
\hline $\begin{array}{l}\text { Age } \\
\text { (years) } \\
\text { /sex }\end{array}$ & $\begin{array}{c}\text { Rat } \\
\text { exposurea; } \\
\text { route of } \\
\text { inoculation }\end{array}$ & $\begin{array}{l}\text { Incu- } \\
\text { bation }\end{array}$ & $\begin{array}{c}\text { Diagnostics; } \\
\text { pathogen }\end{array}$ & $\begin{array}{c}\text { Clinical } \\
\text { features } \\
\text { and compli- } \\
\text { cations }\end{array}$ & $\begin{array}{l}\text { Treatment } \\
\text { regimen }\end{array}$ & $\begin{array}{l}\text { Days of } \\
\text { antibiotic } \\
\text { therapy }^{b}\end{array}$ \\
\hline $5 / M$ & $+; N R$ & Unknown & $\begin{array}{l}\text { Culture -, 16S } \\
\text { RNA +; } \\
\text { S. moniliformis }\end{array}$ & Fever, emesis & $\begin{array}{l}\text { Ceftriaxone, } \\
\text { penicillin }\end{array}$ & 7 (4d IV) \\
\hline $7 / F$ & $+; N R$ & Unknown & $\begin{array}{l}\text { Culture -; } \\
\text { 16S RNA -; } \\
\text { unknown }\end{array}$ & $\begin{array}{l}\text { Fever, rash, } \\
\text { polyarthralgia, } \\
\text { emesis, joint } \\
\text { effusion, sepsis }\end{array}$ & $\begin{array}{l}\text { Gentamicin, } \\
\text { penicillin }\end{array}$ & 14 (7d IV) \\
\hline $14 / F$ & $\begin{array}{l}+; \text { Bite and } \\
\text { scratch }\end{array}$ & 7 days & $\begin{array}{l}\text { Culture +; } \\
\text { S. moniliformis }\end{array}$ & $\begin{array}{l}\text { Fever, myalgia, } \\
\text { rigors }\end{array}$ & $\begin{array}{l}\text { Ceftriaxone, } \\
\text { amoxicillin }\end{array}$ & $16(6 d$ IV) \\
\hline $17 / F$ & $N R$; NR & Unknown & $\begin{array}{l}\text { Culture +; } \\
\text { S. moniliformis }\end{array}$ & $\begin{array}{l}\text { Fever, back } \\
\text { pain }\end{array}$ & Ceftriaxone & Unknown \\
\hline $17 / M$ & $+;$ Scratch & Unknown & $\begin{array}{l}\text { Culture +, 16S } \\
\text { RNA +; } \\
\text { S. moniliformis }\end{array}$ & \begin{tabular}{|l|} 
Fever, \\
polyarthralgia, \\
joint effusion
\end{tabular} & Ceftriaxone & 42 (42d IV) \\
\hline $20 / \mathrm{M}$ & $N R$; NR & Unknown & $\begin{array}{l}\text { Culture +; } \\
\text { S. moniliformis }\end{array}$ & $\begin{array}{l}\text { Fever, rash, } \\
\text { polyarthralgia, } \\
\text { back pain }\end{array}$ & $\begin{array}{l}\text { Ceftriaxone, } \\
\text { penicillin }\end{array}$ & 14 (7d IV) \\
\hline $21 / F$ & + ; Bite & Unknown & $\begin{array}{l}\text { Culture +; } \\
\text { S. moniliformis }\end{array}$ & $\begin{array}{l}\text { Fever, joint } \\
\text { effusion }\end{array}$ & $\begin{array}{l}\text { Ceftriaxone, } \\
\text { penicillin }\end{array}$ & $11(4 d$ IV) \\
\hline $21 / M$ & $+; N R$ & Unknown & $\begin{array}{l}\text { Culture +; } \\
\text { S. moniliformis }\end{array}$ & Fever, myalgia & Doxycycline & 14 (no IV) \\
\hline $28 / F$ & $+; N R$ & Unknown & $\begin{array}{l}\text { Culture +; } \\
\text { S. moniliformis }\end{array}$ & $\begin{array}{l}\text { Fever, rash, } \\
\text { polyarthralgia, } \\
\text { emesis, } \\
\text { diarrhea, } \\
\text { pharyngitis }\end{array}$ & Penicillin & 21 (3d IV) \\
\hline $30 / F$ & + ; Scratch & 8 days & $\begin{array}{l}\text { Culture +; } \\
\text { S. moniliformis }\end{array}$ & $\begin{array}{l}\text { Fever, } \\
\text { polyarthralgia, } \\
\text { emesis, } \\
\text { headaches } \\
\text { query } \\
\text { erythema } \\
\text { nodosum }\end{array}$ & Ceftriaxone & 28 (28d IV) \\
\hline $57 / M$ & + ; Bite & 19 days & $\begin{array}{l}\text { Culture -, 16S } \\
\text { RNA +; } \\
\text { S. moniliformis }\end{array}$ & Fever, rigors & $\begin{array}{l}\text { Ceftriaxone, } \\
\text { doxycycline }\end{array}$ & 38 (28d IV) \\
\hline
\end{tabular}

Abbreviations: d, days; F, Female; IV, intravenous; $M$, male; NR, none reported; RNA, ribonucleic acid; S. moniliformis, Streptobacillus moniliformis; -, negative; + , positive

${ }^{a}$ All exposures were from pet rats

${ }^{b}$ Duration of intravenous therapy in parenthesis

from pet rats. Among the five cases with documented scratches and/or bites, three provided a date of the bite or scratch. The time between exposure and presentation to health care providers were seven, eight and 19 days.

Signs and symptoms documented at initial presentation were included for all 11 cases. Fever, at least intermittently, was reported in all cases (100\%). Pronounced signs and symptoms included polyarthralgia in five cases (45\%), rashes in three cases $(27 \%)$ and joint effusions in three cases (27\%). Other common symptoms included emesis (36\%), myalgia (18\%), rigors (18\%) and back pain (18\%). Two cases (18\%) reported to have complications or potential complications; one had sepsis and the other was suspected to have erythema nodosum, although no further information was subsequently documented.

Ten $(91 \%)$ of the 11 cases were confirmed by microbiology diagnosis, and the remaining case was diagnosed clinically based on history and symptoms. Blood cultures were performed on all cases using routine blood culture media, BD BACTEC Plus Aerobic and BD BACTEC Lytic Anaerobic (Becton Dickinson, Sparks, Maryland). Eight (73\%) were culture-positive for S. moniliformis. Two additional cases were identified based on the presence of $S$. moniliformis $16 \mathrm{~S}$ ribonucleic acid (RNA) within the culture-negative blood culture media or from a joint aspirate. In one case with positive blood cultures, S. moniliformis was also 
successfully identified by 16S RNA analysis of fluid collected from an effused knee joint fluid. With the four most recent cases with positive blood cultures, the blood culture bottles signalled positive within 24 hours of incubation and subcultures of these on solid media demonstrated pinpoint growth of colonies within 48 hours. S. moniliformis was identified by Matrix Assisted Laser Desorption/lonization Time-of-Flight (MALDI-ToF) mass spectrometry (Bruker Daltonics, Billerica, Massachusetts) in these four cases. Non-standardized susceptibility testing found the organisms in these four cases to be susceptible to penicillin and ceftriaxone.

Seven cases required hospitalization; the median length of stay was five days, and the range was three to 17 days. Complete treatment regimens were documented for all cases with the exception of one, which identified the antibiotic but did not describe the length of treatment (Table 1). Ten cases (91\%) used intravenous beta-lactam antibiotics as part of the initial treatment regimen, with ceftriaxone as the most frequently used antibiotic in both the inpatient and outpatient settings. The remaining case used solely oral doxycycline, in part due to the patient's documented penicillin allergy. In nine cases (82\%), treatment was initiated with single-agent antibiotics, while in two cases (18\%), combination antibiotics were used as empiric therapy before adjusting antibiotics based on sensitivities. The median and average total duration of antibiotic therapy was 14 days, but the range varied from seven to 42 days. For all patients who were treated with antibiotics, treatment included a course of outpatient antibiotics with either intravenous or oral stepdown therapy.

\section{Discussion}

This is the largest single case series of RBF published in Canada. A case series from San Diego County, which had a population of $3,095,313$ people in 2010, recorded 17 cases of RBF between 2000 and 2012 (23). Interestingly, in Vancouver Island, which had a population of only 746,058 people in 2010, 11 cases were documented between 2010 and 2016. Thus, the estimated population-corrected annual incidence of RBF on Vancouver Island was 1.34 per million inhabitants per year, compared with San Diego at 0.42 per million inhabitants per year.

There may be several reasons to account for the apparent higher incidence on Vancouver Island. The prevalence of pet rodent ownership may be greater on Vancouver Island, thereby increasing rodent exposure. It is possible that, given the large variability in mucosal colonization by S. moniliformis (3), its prevalence as commensal flora of rats could be higher on Vancouver Island. Alternatively, having all the relevant data from the region centralized within Island Health's Enterprise Data Warehouse may have contributed to a more comprehensive case finding.

On Vancouver Island, S. moniliformis is the only identified causative pathogen of RBF. Within this case series, fever was a feature of all documented cases; however, the other classic RBF findings of rash and polyarthralgia were documented in only three $(27 \%)$ and five (45\%) cases, respectively. After fever and polyarthralgia, emesis was the third most common symptom afflicting four (36\%) of cases. The remaining signs and symptoms, including myalgia, headaches and pharyngitis, were seen in fewer than one-third of the cases; consistent with a previous meta-analysis of case reports (4). Further signs and symptoms such as joint effusions, back pain, rigors and diarrhea were also documented.

Despite the broad susceptibility of S. moniliformis to many classes of antibiotics, current recommendations for treatment of RBF is penicillin $(3,15)$. In this case series, ceftriaxone was the most common empiric antibiotic choice and was a component of therapy in eight (73\%) of cases; however, penicillin was the most common stepdown therapy (Table 1). Alternatives, including gentamicin, doxycycline and amoxicillin, were used without complications. Of note, one patient responded to a 14-day course of oral doxycycline alone.

While RBF carries roughly a $10 \%$ mortality in those who do not receive treatment $(7,10,24)$, no mortality was observed in this case series as timely treatment was provided in all cases. Similarly, previously published studies have shown that the outcomes of RBF are favorable when treatment was provided and no long-term morbidity or mortality were identified. This further supports the idea that awareness, recognition and judicious antibiotic treatment are significant contributors to positive patient outcomes.

There are several limitations to this retrospective study that are related to the breadth and depth of information. Despite a comprehensive search for RBF cases within Island Health, cases may be missed: patients who were diagnosed as outpatients and their blood cultures were negative or were not performed; patients from Vancouver Island who were diagnosed and managed outside of Vancouver Island; and patients for whom detailed information about rodent exposure was not recorded. Moving forward, efforts should be made to estimate the risk of developing RBF upon a scratch, bite or other significant exposure to rat saliva, urine or feces. In one case, it was noted that the patient had been bitten and scratched by his or her pet rat numerous times in the preceding months before subsequently developing RBF. Next steps in the research into RBF should include a province-wide analysis to determine if the rates of RBF on Vancouver Island are higher than the remainder of British Columbia as this may point to either a failure to recognize RBF elsewhere in the province or a local factor or factors contributing to higher prevalence on Vancouver Island.

\section{Conclusion}

This study represents the largest single case series of RBF in Canada to date. It also suggests a higher than expected incidence of RBF on Vancouver Island. RBF is a rare disease, but may be underreported due to the non-specific presentation and challenges with laboratory diagnosis. To detect RBF, a high index of suspicion is needed that would lead to an inquiry regarding a patient's exposure to rodents in those with symptoms of fever with rash, polyarthralgia, emesis, myalgia or joint effusions. Blood culture is needed to confirm the diagnosis.

Rat bite fever remains a serious and under recognized infection. Further study may assist in getting an accurate picture of the epidemiology of RBF in Canada. 


\section{Authors' statement}

The authors contributed equally to this manuscript

$\mathrm{BH}$ - Conceptualization, methodology, investigation, writing-original draft, review and editing

CW - Conceptualization, methodology, investigation, writing-original draft, review and editing

KT - Conceptualization, methodology, resources, writing-review and editing

The views expressed in the submitted article are those of the authors and are not an official position of the University of British Columbia.

\section{Conflict of interest}

None.

\section{Acknowledgements}

We would like to thank the clinicians and allied-health care teams involved in providing care to the patients infected with RBF. Further, we would like to thank Rebecca Raworth, Island Medical Program Librarian, for her support in the literature review process.

\section{Funding}

None.

\section{References}

1. Dendle C, Woolley IJ, Korman TM. Rat-bite fever septic arthritis: illustrative case and literature review. Eur J Clin Microbiol Infect Dis 2006 Dec;25(12):791-7. https://doi. org/10.1007/s10096-006-0224-x. PubMed (https://www.ncbi. nlm.nih.gov/pubmed/17096137?dopt=Abstract)

2. Suzuki K, Hirai Y, Morita F, Nakamura A, Uehara Y, Naito T. Streptobacillus moniliformis Bacteremia in a Pet Shop Employee: Case Report and Literature Review. Open Forum Infect Dis 2017 Mar;4(2):ofx038. https://doi.org/10.1093/ ofid/ofx038. PubMed (https://www.ncbi.nlm.nih.gov/ pubmed/28730157?dopt=Abstract)

3. Centers for Disease Control and Prevention (CDC). Rat-bite fever--New Mexico, 1996. MMWR Morb Mortal Wkly Rep 1998 Feb;47(5):89-91. PubMed (https://www.ncbi.nlm.nih.gov/ pubmed/28730157?dopt=Abstract)

4. Elliott SP. Rat bite fever and Streptobacillus moniliformis. Clin Microbiol Rev 2007 Jan;20(1):13-22. https://doi.org/10.1128/ CMR.00016-06. PubMed (https://www.ncbi.nlm.nih.gov/ pubmed/17223620?dopt=Abstract)

5. Graves MH, Janda JM. Rat-bite fever (Streptobacillus moniliformis): a potential emerging disease. Int J Infect Dis 2001;5(3):151-5. https://doi.org/10.1016/S12019712(01)90090-6. PubMed (https://www.ncbi.nlm.nih.gov/ pubmed/11724672?dopt=Abstract)

6. Hirschhorn RB, Hodge RR. Identification of risk factors in rat bite incidents involving humans. Pediatrics
1999 Sep;104(3):e35. https://doi.org/10.1542/ peds.104.3.e35. PubMed (https://www.ncbi.nlm.nih.gov/ pubmed/10469818?dopt=Abstract)

7. Centers for Disease Control and Prevention (CDC). Fatal rat-bite fever--Florida and Washington, 2003. MMWR Morb Mortal Wkly Rep 2005 Jan;53(51):1198-202. PubMed (https:// www.ncbi.nlm.nih.gov/pubmed/15635289?dopt=Abstract)

8. Ordog GJ, Balasubramanium S, Wasserberger J. Rat bites: fifty cases. Ann Emerg Med 1985 Feb;14(2):126-30. https://doi. org/10.1016/S0196-0644(85)81073-8. PubMed (https://www. ncbi.nlm.nih.gov/pubmed/3970397?dopt=Abstract)

9. Eisenberg T, Ewers C, Rau J, Akimkin V, Nicklas W. Approved and novel strategies in diagnostics of rat bite fever and other Streptobacillus infections in humans and animals. Virulence 2016 Aug;7(6):630-48. https://doi.org/10.1080/2150559 4.2016.1177694. PubMed (https://www.ncbi.nlm.nih.gov/ pubmed/27088660?dopt=Abstract)

10. Ojukwu IC, Christy C. Rat-bite fever in children: case report and review. Scand J Infect Dis 2002;34(6):474-7. https://doi. org/10.1080/003655402320170345. PubMed (https://www. ncbi.nlm.nih.gov/pubmed/12160180?dopt=Abstract)

11. Carbeck RB, Murphy JF, Britt EM. Streptobacillary rat-bite fever with massive pericardial effusion. JAMA 1967 Aug;201(9):703-4. https://doi.org/10.1001/ jama.1967.03130090067024. PubMed (https://www.ncbi.nlm. nih.gov/pubmed/5340333?dopt=Abstract)

12. Faro S, Walker C, Pierson RL. Amnionitis with intact amniotic membranes involving Streptobacillus moniliformis. Obstet Gynecol 1980 Mar;55(3 Suppl):9S-11S. https://doi. org/10.1097/00006250-198003001-00003. PubMed (https:// www.ncbi.nlm.nih.gov/pubmed/7360458?dopt=Abstract)

13. Tattersall RS, Bourne JT. Systemic vasculitis following an unreported rat bite. Ann Rheum Dis 2003 Jul;62(7):605-6. https://doi.org/10.1136/ard.62.7.605. PubMed (https://www. ncbi.nlm.nih.gov/pubmed/12810419?dopt=Abstract)

14. Kondruweit M, Weyand M, Mahmoud FO, Geissdörfer W, Schoerner C, Ropers D, Achenbach S, Strecker T. Fulminant endocarditis caused by Streptobacillus moniliformis in a young man. J Thorac Cardiovasc Surg 2007 Dec;134(6):1579-80. https://doi.org/10.1016/j.jtcvs.2007.08.010. PubMed (https:// www.ncbi.nlm.nih.gov/pubmed/18023687?dopt=Abstract)

15. Vetter NM, Feder HM, Ratzan RM. Rat bite fever caused by a kiss. Am J Emerg Med. 2016 Jun;34(6):1190.e3-4. https://doi. org/10.1016/j.ajem.2015.11.051. PubMed (https://www.ncbi. nlm.nih.gov/pubmed/26698680)

16. Booth $\mathrm{CM}$, Katz KC, Brunton J. Fever and a rat bite. Can J Infect Dis 2002 Jul;13(4):269-72. https://doi. org/10.1155/2002/673126. PubMed (https://www.ncbi.nlm.nih. gov/pubmed/18159400?dopt=Abstract)

17. Holden FA, Mackay JC. Rat bite fever--An occupational hazard. Can Med Assoc J. 1964 Jul 11;91:78-81. PubMed (https:// www.ncbi.nlm.nih.gov/pubmed/14154300)

18. Dolman CE, Kerr DE, Chang H, Shearer AR. Two cases of rat bite fever due to Streptobacillus moniliformis. Can J Public Health. 1951 Jun;42(6):228-41. PubMed (https://www.ncbi. nlm.nih.gov/pubmed/14839574)

19. Abdulaziz H, Touchie C, Toye B, Karsh J. Haverhill fever with spine involvement. J Rheumatol 2006 Jul;33(7):1409-10. PubMed (https://www.ncbi.nlm.nih.gov/pubmed/16821275)

20. Schachter ME, Wilcox L, Rau N, Yamamura D, Brown $\mathrm{S}$, Lee $\mathrm{CH}$. Rat-bite fever, Canada. Emerg Infect Dis 
2006 Aug;12(8):1301-2. https://doi.org/10.3201/ eid1208.060044. PubMed (https://www.ncbi.nlm.nih.gov/ pubmed/16972359?dopt=Abstract)

21. Khatchadourian $K$, Ovetchkine $P$, Minodier $P$, Lamarre $V$, Lebel $\mathrm{MH}$, Tapiéro $\mathrm{B}$. The rise of the rats: A growing paediatric issue. Paediatr Child Health 2010 Mar:15(3):131-4. https://doi. org/10.1093/pch/15.3.131. PubMed (https://www.ncbi.nlm.nih. gov/pubmed/21358889?dopt=Abstract)

22. McKee G, Pewarchuk J. Rat-bite fever. CMAJ 2013 Oct;185(15):1346. https://doi.org/10.1503/ cmaj.121704. PubMed (https://www.ncbi.nlm.nih.gov/ pubmed/23529964?dopt=Abstract)
23. Adam JK, Varan AK, Pong AL, McDonald EC; Centers for Disease Control and Prevention (CDC). Notes from the field: fatal rat-bite fever in a child - San Diego County, California, 2013. MMWR Morb Mortal Wkly Rep 2014 Dec;63(50):1210-1. PubMed (https://www.ncbi.nlm.nih.gov/ pubmed/25522092?dopt=Abstract)

24. Thong BY, Barkham TM. Suppurative polyarthritis following a rat bite. Ann Rheum Dis 2003 Sep;62(9):805-6. https://doi. org/10.1136/ard.62.9.805. PubMed (https://www.ncbi.nlm.nih. gov/pubmed/12922949?dopt=Abstract)

\section{CCDR}

VISUAL ABSTRACT

\section{Rat bite fever is rare}

Rate bite fever (RBF) is a rare infection caused by bacteria and is part of the normal flora in the mouths of rodents (rats, mice, gerbils, etc.).

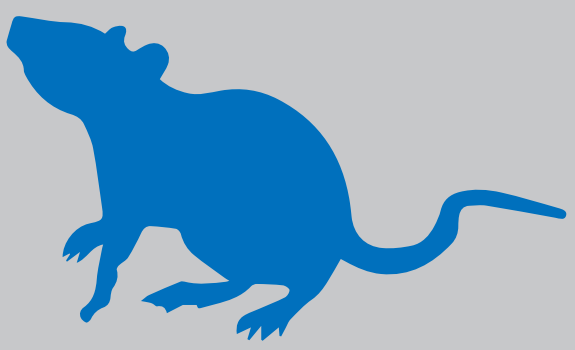

RBF is caused by bites, scratches, and contact with rodent urine or feces. Symptoms include fever, chills, rash, muscle aches, and joint pain.

\section{RAT BITE FEVER (RBF) ON VANCOUVER ISLAND: RARE BUT HIGHER THAN EXPECTED}

\section{More cases than expected}

There were 11 cases reported on Vancouver Island between 2010-2016.* Seven cases required hospitalization.

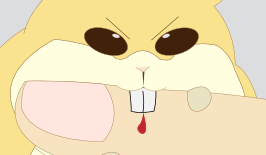

As more people have rodents as pets, exposure and risk of contracting the disease has increased.

\section{RBF is treatable and preventable}

\section{TREATMENT}

Rat bite fever is easily treated with antibiotics; it can be a serious illness if left untreated.

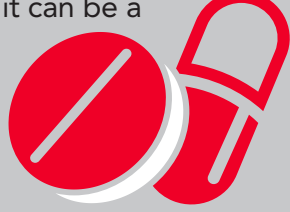

\section{PREVENTION}

If you have a rodent as a pet, wash your hands thoroughly after handling

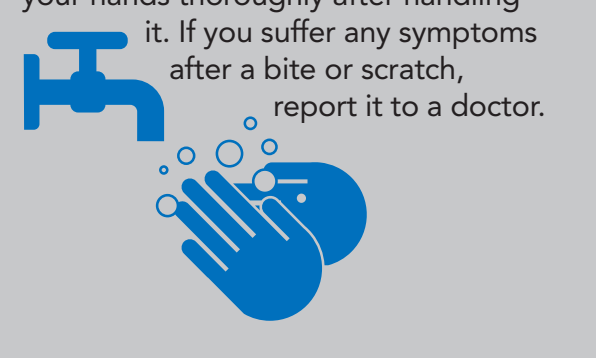

*Reference: Hryciw BN, Wright CP, Tan K. Rat bite fever on Vancouver Island. Can Commun Dis Rep 2018;44(9):215-9. https://doi.org/10.14745/ccdr.v44i09a05 